\title{
Relação da idade na presença de bactérias resistentes a antimicrobianos em rebanhos leiteiros no Rio Grande do Sul ${ }^{1}$
}

\author{
Waldemir Santiago-Neto ${ }^{2,3 *}$, Gustavo Machado ${ }^{2,3}$, Daniel S. Paim ${ }^{3}$, Thais de Campos ${ }^{3}$, \\ Maria A.V.P. Brito ${ }^{4}$, Marisa R.I. Cardoso ${ }^{3}$ e Luís G. Corbellini ${ }^{2,3}$
}

\begin{abstract}
Santiago-Neto W., Machado G., Paim D.S., Campos T., Brito M.A.V.P., Cardoso M.R.I. \& Corbellini L.G. 2014. [Age related to the presence of antimicrobial resistant bacteria in twenty one dairy herds in Rio Grande do Sul, Brazil.] Relação da idade na presença de bactérias resistentes a antimicrobianos em rebanhos leiteiros no Rio Grande do Sul. Pesquisa Veterinária Brasileira 34(7):613-620. Laboratório de Epidemiologia Veterinária, Faculdade de Veterinária, Universidade Federal do Rio Grande do Sul, Av. Bento Gonçalves 9090, Porto Alegre, RS 91540-000, Brazil. E-mail: wal_sanet@hotmail.com

Bovine mastitis is an important disease in dairy cattle due to its high incidence and economic losses associated mainly with reduced milk production and treatment costs. The use of antimicrobials to treat clinical cases and at dry off raises the concern of selection of resistant bacterial strains. This may also reflect on public health, since resistant bacteria, such as methicillin-resistant Staphylococcus aureus (MRSA), may be transmitted to humans by direct contact with infected animals or by dairy products. The resistance of bacteria to antimicrobials has risen, in general, due to ineffective therapy. Studies in Brazil with non-random samples show increase in resistance pattern, mainly in S. aureus. The exposition to repeated antimicrobial treatment throughout the consecutive lactations of cows may be a predisposing factor to development of antimicrobial resistance in bacteria that infect the udder. Thus, the aim of this study was to determine the possible causal association between antimicrobial resistance in bacteria isolated from bovine udder milk and animal data such as age and lactation period. Milk samples were collected from 21 randomly selected dairy herds from Rio Grande do Sul, southernmost Brazilian state, from the target population of 1656 semi-intensive dairy farms, stratified by her size. The sample unit was considered the bacteria, and for the prevalence estimation a frequency of 35\% Staphylococcus sp. penicillin resistant; an absolute precision of $12 \%$; and $90 \%$ confidence level were used. Bacteria were isolated from composite milk samples obtained from all quarters of each cow after discarding the initial three or four streams of milk. To access potential risk factors, animal characteristics were obtained through an interview with the producers. Laboratory tests were done according to National Mastitis Council recommendations. A total of 242 isolates was obtained from 195 cows out of 251 cows sampled. The prevalence of animal infections was described in groups according to the epidemiological profile: environmental, contagious and other bacteria. These were $57.3 \%, 26.3 \%$ and $11.2 \%$, respectively of the sampled animals. Antimicrobial susceptibility tests against 12 different antimicrobials were performed in 159 isolates. Altogether, $30 \%$ of the isolates tested showed resistance to at least three different antimicrobial groups and were classified as multidrug-resistant. Higher frequencies of resistance were observed against ampicillin to coagulase-negative sta-
\end{abstract}

${ }^{1}$ Recebido em 8 de março de 2014.

Aceito para publicação em 7 de maio de 2014.

${ }^{2}$ Laboratório de Epidemiologia Veterinária (EPILAB), Universidade Federal do Rio Grande do Sul, Av. Bento Gonçalves 9090, Porto Alegre, RS 91540000, Brasil. *Autor para correspondência: wal_sanet@hotmail.com

\footnotetext{
${ }^{3}$ Departamento de Medicina Veterinária Preventiva,Universidade Federal do Rio Grande do Sul, Av. Bento Gonçalves 9090, Porto Alegre, RS 91540-000.

${ }^{4}$ Embrapa Gado de Leite, Rua Eugênio do Nascimento 610, Dom Bosco, Juiz de Fora, MG 36038-330, Brasil.
} 
phylococci, followed by erythromycin to coagulase-positive staphylococci and tetracycline to streptococci. The logistic regression analysis showed a significant relationship between age of the cows and presence of multidrug-resistant coagulase-positive staphylococci and distribution of different class of bacteria, suggesting a competition dynamic throughout the ages $(\mathrm{p}<0.05)$. Animals with three to four years old had 13.7 times more chances $\left(\mathrm{IC}_{95 \%}\right.$ $1.4-130.2 ; p=0,02$ ) to have multidrug-resistant coagulase-positive staphylococci compared to those with two to three years. Time of exposure to infectious agents and consequent therapies suggests a greater chance of udder's colonization by resistant pathogens due to repeatedly selection pressure during lifetime.

INDEX TERMS: Antimicrobial resistance, coagulase-positive staphylococci, coagulase-negative staphylococci, ageing epidemiology, dairy cattle.

RESUMO.- A mastite bovina é uma doença importante na bovinocultura de leite, devido à sua alta incidência e perdas econômicas associadas principalmente com a produção de leite reduzida e aos custos do tratamento. 0 uso de antimicrobianos para o tratamento de casos clínicos e no período seco tem levantado preocupações quanto à seleção de cepas bacterianas resistentes. Isso também pode refletir na saúde pública, uma vez que bactérias resistentes, como o Staphylococcus aureus meticilina-resistente (MRSA), podem ser transmitidas aos seres humanos por contato direto com animais infectados ou produtos lácteos. A resistência das bactérias aos agentes antimicrobianos aumentou, em geral, devido a tratamentos ineficazes. Estudos realizados no Brasil com amostras não planejadas mostram aumento no padrão de resistência, principalmente em $S$. aureus. A exposição ao tratamento antimicrobiano repetido ao longo das lactações consecutivas de vacas pode ser um fator predisponente para o desenvolvimento da resistência antimicrobiana em bactérias que infectam o úbere. Assim, o objetivo deste estudo foi determinar a possível associação causal entre resistência antimicrobiana em bactérias isoladas a partir do leite bovino e dados como idade e período de lactação. As amostras de leite foram coletadas de 21 rebanhos leiteiros do Rio Grande do Sul, Brasil, selecionados aleatoriamente a partir da população-alvo de 1.656 explorações leiteiras semi-intensivas, estratificada por tamanho do rebanho. A bactéria foi considerada a unidade amostral, e para a estimativa de prevalência foram utilizados os seguintes parâmetros: uma frequência de 35\% de Staphylococcus sp. resistentes à penicilina; um nível de confiança de 90\%; e uma precisão absoluta de $12 \%$. As bactérias foram isoladas de amostras de leite compostas de todos os quartos mamários de cada vaca após descartar os primeiros três ou quatro jatos de leite. Para acessar os potenciais fatores de risco, características dos animais foram obtidas através de uma entrevista com os produtores. Os exames laboratoriais foram realizados de acordo com as recomendações do National Mastitis Council. Um total de 242 isolados foi obtido de 195 vacas a partir da amostra do rebanho total (251 vacas). A prevalência de infecções foi descrita em grupos de acordo com o perfil epidemiológico: bactérias ambientais, contagiosas e outras. Estas perfizeram 57,3\%, 26,3\% e $11,2 \%$, respectivamente, dos animais amostrados. Testes de suscetibilidade antimicrobiana contra 12 diferentes antimicrobianos foram realizados em 159 isolados. No total, $30 \%$ dos isolados testados mostraram resistência a pelo menos três grupos diferentes de antimicrobianos e foram classificados como multirresistentes. Foram observadas as freqüências mais elevadas de resistência contra a ampicilina para os estafilococos coagulase-negativo, seguida de eritromicina para estafilococos coagulase-positivo e tetraciclina para estreptococos. A análise de regressão logística mostrou uma relação significativa entre a idade das vacas e a presença de estafilococos coagulase-positivo multirresistentes e distribuição de classes diferentes de bactérias nos diferentes estratos etários, o que sugere uma concorrência dinâmica ao longo do tempo $(p<0,05)$. Animais com três a quatro anos tiveram 13,7 vezes mais chances ( IC $_{95 \%} 1,4$ - 130,2, p = 0,02) de ter estafilococos coagulase-positivo multirresistentes em comparação com aqueles com dois ou três anos. 0 tempo de exposição a agentes infecciosos e consequentes terapias sugere uma maior chance de colonização do úbere por patógenos resistentes devido à pressão de seleção repetida durante a vida.

TERMOS DE INDEXAÇÃO: Resistência antimicrobiana, estafilococos coagulase-positivo, estafilococos coagulase-negativo, epidemiologia do envelhecimento, bovinos de leite.

\section{INTRODUÇÃO}

A mastite bovina é uma doença importante para a bovinocultura leiteira, devido à alta incidência de casos clínicos e subclínicos e aos prejuízos econômicos que acarreta. A mastite resulta da infecção da glândula mamária, principalmente por bactérias dos gêneros Staphylococcus, Streptococcus e Gram-negativos do grupo dos coliformes (Ruegg 2012).

Na pecuária leiteira, é a doença que demanda maior emprego de antimicrobianos (Erskine et al. 2004) administrados para tratamento dos casos clínicos e na terapia da vaca seca. Em alguns estudos, o uso terapêutico e preventivo de antimicrobianos na mastite não foi relacionado ao aumento ou emergência da resistência entre os patógenos da mastite (Erskine et al. 2002, Erskine et al. 2004). Entretanto, variações nos índices de resistência são observadas entre regiões ou rebanhos devido à pressão seletiva exercida pelo agente antimicrobiano (O'Brien 2002 apud Rajala-Schultz et al. 2004). A antibioticoterapia executada contínua e imprudentemente é relatada como fator determinante para a seleção de cepas resistentes, podendo repercutir sobre a saúde pública (Piddock 1996, OIE 2008b). Estudos têm sugerido o potencial de seleção de cepas devido ao tratamento no período seco e à idade das vacas em combinação com alta contagem de células somáticas e histórico de mastite 
clínica (Rajala-Schultz et al. 2009), demonstrando a complexidade de avaliar-se tal risco.

Entre os agentes da mastite, as bactérias do gênero Staphylococcus têm apresentado maior resistência aos antimicrobianos, sobretudo Staphylococcus aureus, com destaque para a resistência aos antibióticos beta-lactâmicos (Brito et al. 2001, Pitkälä et al. 2004, Olsen et al. 2006,). Entretanto, estafilococos coagulase-negativos (ECN) tem sido indicados como protetores contra infecções por patógenos mais virulentos (Schukken et al. 1989) e, por outro lado, tendem a ser mais resistentes quando comparados a $S$. aureus e com facilidade desenvolvem multirresistência (Pitkälä et al. 2004), servindo como reservatório de genes de resistência.

A idade é um reconhecido fator de risco, ou predisponente, contribuindo para a ocorrência de doenças multifatoriais, sendo o conhecimento do seu papel relevante particularmente para a estimação de morbimortalidade das doenças em populações e identificação de causas das doenças (Thrusfield 2010). 0 monitoramento periódico das mudanças na prevalência de bactérias resistentes a nível animal constitui uma parte essencial na estratégia destinada a limitar a propagação da resistência antimicrobiana e otimiza a escolha dos antimicrobianos utilizados na terapia (OIE 2008a).

O objetivo deste estudo foi avaliar a possível associação causal entre variáveis de desfecho (1 e 2) e variáveis preditoras (3): (1) a prevalência de bactérias relevantes causadoras de mastite na glândula mamária de bovinos, destacando o gênero Staphylococcus, e (2) a resistência dessas bactérias aos antimicrobianos, e (3) fatores ligados ao hospedeiro como a idade, número de partos e dias em lactação.

\section{MATERIAL E MÉTODOS}

\section{Amostragem}

O cálculo da amostra considerou a bactéria como unidade primária visando saber quantos rebanhos seriam necessários para obter o número de isolados de Staphylococcus spp. necessário para estimar a frequência de resistência aos antibióticos beta-lactâmicos. Os parâmetros utilizados para o cálculo da amostra foram: frequência de Staphylococcus spp. resistentes à penicilina de 35\% (Brito et al. 2001); precisão absoluta de 12\%; e nível de confiança de $90 \%$. O cálculo de amostra baseou-se no gênero Staphylococcus, por ser este o microrganismo mais isolado na glândula mamária de bovinos.

Em janeiro de 2010, foram amostrados aleatoriamente 21 rebanhos da população alvo, constituída de 1656 propriedades leiteiras de criação semi-intensiva do Rio Grande do Sul estratificadas por tamanho de rebanho. Foram coletadas amostras de leite de todas as vacas em lactação nas propriedades amostradas, totalizando 251 animais. As amostras foram compostas, isto é, formadas por alíquotas de leite colhidas dos quartos de cada vaca. Antes da coleta foi feita a antissepsia dos tetos e descarte dos primeiros jatos. As amostras foram acondicionadas em frascos individuais estéreis e armazenadas em caixa isotérmicas. Dados dos animais - idade, número de lactações e período em lactação - foram obtidos por meio de entrevista realizada com os produtores. As análises foram realizadas no Setor de Medicina Veterinária Preventiva da Faculdade de Veterinária da Universidade Federal do Rio Grande do Sul.

\section{Exames microbiológicos}

A cultura das amostras de leite foi realizada semeando-se volumes de 0,01mL em ágar sangue contendo $5 \%$ de sangue desfibrinado de carneiro, seguindo-se incubação a $37^{\circ} \mathrm{C}$ durante $24-48 \mathrm{~h}$. As colônias foram analisadas segundo recomendações do National Mastitis Council (NMC 2004) quanto à morfologia, padrões hemolíticos, coloração de Gram e testes bioquímicos. Os microrganismos isolados foram classificados em grupos (contagioso, ambiental e outros), considerando a epidemiologia da infecção do úbere.

\section{Teste de suscetibilidade aos antimicrobianos}

Foi empregado o teste de ágar-difusão para testar a suscetibilidade dos isolados de Staphylococcus spp., Streptococcus spp. e Enterococcus spp., seguindo as recomendações do Clinical Laboratory Standard Institute (CLSI 2008). S. aureus ATCC 29213 foi empregado como controle dos testes. Foram testados discos impregnados com os seguintes antimicrobianos (Oxoid, USA, Columbia, Maryland): ampicilina $10 \mu \mathrm{g}$, cefalotina $30 \mu \mathrm{g}$, ceftiofour $30 \mu \mathrm{g}$, clindamicina $2 \mu \mathrm{g}$, enrofloxacina $5 \mu \mathrm{g}$, eritromicina $15 \mu \mathrm{g}$, gentamicina $10 \mu \mathrm{g}$, oxacilina $1 \mu \mathrm{g}$, penicilina 10 Unidades, trimetoprima/ sulfametoxazol 1,25/23,75 $\mu$; sulfonamida $300 \mu \mathrm{g}$; e tetraciclina $30 \mu \mathrm{g}$. De acordo com o critério interpretativo das zonas de inibição, as bactérias foram classificadas em resistentes (R), intermediárias (I) ou suscetíveis (S) aos antimicrobianos testados. Bactérias resistentes a três ou mais classes de antimicrobianos foram consideradas multirresistentes (Schwarz et al. 2010).

\section{Análise estatística}

As características dos animais - idade, período de lactação, raça e número de partos - foram descritas quanto às distribuições de frequência e compiladas aos resultados dos isolados e dos perfis de sensibilidade encontrados. Os indicadores analisados na estatística descritiva foram: (1) animais com pelo menos um patógeno relevante em mastite bovina (animais infectados), (2) infecções por Staphylococcus spp. e (3) infecções por Staphylococcus spp. multirresistentes. As variáveis: idade animal, partos e dias em lactação foram categorizadas de acordo com seus quartis por faixa etária em anos [(1) dois a três, (2) quatro a cinco, (3) seis a sete e (4) mais que sete], por número de partos [(1) um ou dois, (2) três ou quatro e (3) mais de quatro], e por quartis dos dias em lactação [(1) até 82, (2) 82 a 180, (3) 180 a 245 e (4) mais que 245].

A unidade amostral utilizada na análise estatística para verificar a hipótese de associação entre multirresistência e o hospedeiro foi a vaca lactante. Foram incluídos na regressão logística 156 animais, os quais dispunham de dados completos para a análise, a saber, idade, número de partos e período de lactação (variáveis preditoras) e, também, resultados de isolamento e perfis de sensibilidade aos antimicrobianos (variáveis de desfecho). Foram construídos dois modelos de regressão logística univariada para verificar se haveria associação entre as variáveis preditoras 
mencionadas e as variáveis de desfecho - (1) colonização por Staphylococcus spp. (coagulase-negativos e positivos) e (2) colonização por um microrganismo resistente (a pelo menos uma classe ou a mais de três classes antimicrobianas). A associação foi investigada a nível individual utilizando valor de $p$ crítico 0,05 . 0 modelo de regressão foi construído no SAS 9.2®. Variáveis com associação significativa foram consideradas para discussão do desfecho. Odds ratios (ORs), valores de $p$ e intervalos de confiança de $95 \%$ foram reportados. Além disso, a partir da observação da estatística descritiva foi utilizado o teste de qui-quadrado para verificar a diferença de resistência à tetraciclina entre Streptococcus spp. e Staphylococcus spp.

\section{RESULTADOS}

\section{Estatística descritiva}

0 número de animais por rebanho variou de três a 53 , sendo a moda sete animais. Em $67 \%$ dos rebanhos (14/21) havia no máximo dez animas em lactação. A raça predominante foi a Holandesa (95\%). A idade média dos animais ( $\mathrm{n}=156$ ) foi 5,2 anos; o número médio de partos foi 3,2; e a média dos dias em lactação foi 181,2. Em 76\% dos rebanhos foram encontrados agentes associados à mastite em pelo menos um animal (16/21).

Estafilococos coagulase-positivo (ECP), ECN, Streptococcus agalactiae, Corynebacterium sp., Streptococcus uberis, Streptococcus dysgalactiae, Enterococcus sp. e Escherichia coli foram identificados nas amostras, perfazendo 242 isolados ao total (Quadro 1). Em 77,7\% dos animais (195/251) houve o isolamento de pelo menos uma bactéria a partir das amostras de leite (Quadro 1), sendo que destes, $22,5 \%$ (44/195) apresentaram crescimento de mais de um agente e 12,3\% (24/195) de dois grupos epidemiológicos distintos (por exemplo, um ambiental e outro contagioso na mesma amostra).

Do total de isolados analisados pelo teste de suscetibilidade $(n=159), 58,5 \%(93 / 159)$ apresentavam resistência ao menos a um dos antimicrobianos. Os maiores índices de resistência foram para o grupo dos beta-lactâmicos testados (44\%) e eritromicina (42,8\%). 0 maior percentual de resistência dos ECN foi justamente aos

\begin{tabular}{|c|c|c|}
\hline $\begin{array}{r}\text { Quadro 1. Di } \\
\text { animais con } \\
\text { partir da an } \\
\text { microrganisn } \\
\text { lactação am }\end{array}$ & $\begin{array}{l}\text { liçáo das frequênci } \\
\text { amento de pelo mer } \\
\text { a de leite, de acordo } \\
\text { ausadores de mastit } \\
\text { Idas de } 21 \text { rebanhos } \\
\text { Grande do Sul }\end{array}$ & $\begin{array}{l}\text { bactérias e de } \\
\text { Ima bactéria a } \\
\text { as classes de } \\
251 \text { vacas em } \\
\text { Estado do Rio }\end{array}$ \\
\hline $\begin{array}{c}\text { Classe de } \\
\text { Microrganismos }^{\mathrm{a}}\end{array}$ & $\begin{array}{l}\text { Número de bactérias } \\
\text { isoladas }(\mathrm{N}=242) \mathrm{n}(\%)\end{array}$ & $\begin{array}{l}\text { Número de animais } \\
(\mathrm{N}=251) \mathrm{n}(\%)\end{array}$ \\
\hline Ambientais & $145(59,9)$ & $144(57,3)$ \\
\hline Contagiosos & $69(28,5)$ & $66(26,3)$ \\
\hline Outros & $28(11,6)$ & $28(11,2)$ \\
\hline NHC (Negativos) & - & $56(22,3)$ \\
\hline
\end{tabular}

${ }^{a}$ Ambientais = ECN (estafilococos coagulase-negativo), Klebsiella sp., Escherichia coli, Enterococcus sp. e gênero Streptococcus exceto S. agalactiae. . Contagiosos = ECP (estafilococos coagulase-positivo), S. agalactiae e Corynebacterium sp. Outros = Arcanobacterium sp., Nocardia sp. e leveduras ; NHC = não houve crescimento relevante conferindo um status negativo ao animal.
Quadro 2. Distribuição dos microrganismos ( $n=159)$ resistentes a diferentes classes de antimicrobianos isolados de amostras de leites de 251 vacas em lactação de 21 rebanhos no Rio Grande do Sul

\begin{tabular}{|c|c|c|c|c|}
\hline \multirow[t]{2}{*}{ Classe de Antimicrobianos } & \multicolumn{4}{|c|}{ Isolados resistentes no antibiograma (\%) } \\
\hline & $\begin{array}{c}\mathrm{ECN}^{\mathrm{a}} \\
(\mathrm{n}=84)\end{array}$ & $\begin{array}{c}\mathrm{ECP} \\
(n=57)\end{array}$ & $\begin{array}{l}\text { Streptococcus } \\
\quad(\mathrm{n}=18)\end{array}$ & $\begin{array}{c}\text { Total } \\
(\mathrm{n}=159)\end{array}$ \\
\hline $\begin{array}{l}\text { Beta Lactâmicos } \\
\text { (Ampicilina, Penicilina e Oxacilina) }\end{array}$ & 48,8 & 43,8 & 22,2 & 44 \\
\hline $\begin{array}{l}\text { Cefalosporinas } \\
\text { (Ceftiofur/ Cefalotina) }\end{array}$ & 10,7 & 31,6 & 11,1 & 18,2 \\
\hline $\begin{array}{l}\text { Lincosamidas } \\
\text { (Clindamicina) }\end{array}$ & 16,6 & 35 & 33,3 & 25,2 \\
\hline $\begin{array}{l}\text { Fluorquinolonas } \\
\text { (Enrofloxacina) }\end{array}$ & 19 & 29,8 & 5,5 & 21,4 \\
\hline $\begin{array}{l}\text { Macrolídeos } \\
\text { (Eritromicina) }\end{array}$ & 41,6 & 50,9 & 22,2 & 42,8 \\
\hline $\begin{array}{l}\text { Aminoglicosídeos } \\
\text { (Gentamicina) }\end{array}$ & 11,9 & 26,3 & 11,1 & 17 \\
\hline $\begin{array}{l}\text { Inibidores do Ácido Fólico } \\
\text { (Sulfametoxazol/Trimetoprim+Sulfa.) }\end{array}$ & 15,5 & 24,5 & 27,8 & 20,1 \\
\hline Tetraciclinas & 5,9 & 10,5 & 55,5 & 13,2 \\
\hline $\begin{array}{l}\text { Resistência a pelo menos uma classe } \\
\text { de antimicrobianos }\end{array}$ & 55,9 & 54,4 & 83,3 & 58,5 \\
\hline Multirresistentes ( $>3$ classes $)$ & 23,8 & 40,35 & 27,8 & 30,2 \\
\hline
\end{tabular}

a Estafilococos coagulase-negativo, ${ }^{\mathrm{b} E s t a f i l o c o c o s}$ coagulase-positivo.

beta-lactâmicos (48,8\%), enquanto que $50,9 \%$ dos ECP isolados foram resistentes à eritromicina. Dentre todos os isolados resistentes, 58,5\% (93/159) apresentaram resistência ao menos a um antimicrobiano e $30,2 \%$ (48/159) ao menos a três grupos antimicrobianos (multirresistentes) (Quadro 2).

A análise de regressão logística, considerando animais que apresentavam dados demográficos completos e respectivos microrganismos isolados submetidos ao teste de suscetibilidade a antimicrobianos (gêneros Staphylococcus e Streptococcus), evidenciou a associação significativa ( $p$ $\leq 0,05)$ entre (a) prevalência das principais bactérias isoladas (ECP e ECN - variáveis de desfecho) e a faixa etária (variável explanatória) e (b) a presença de resistência aos antimicrobianos testados (variável de desfecho) e a faixa etária e número de partos das vacas (variáveis explanatórias). As distribuições de prevalência de colonização e de resistência estão demonstradas no Quadro 3, por estrato de idade e de número de partos de acordo com a análise.

\section{Prevalência bacteriana e idade como fator de risco}

Houve um risco 3,5 vezes maior em vacas com mais de sete anos apresentarem colonização por ECP quando comparadas com vacas de dois a três anos de idade $(\mathrm{OR}=3,56$; $\mathrm{IC}_{95 \%}=1,3-9,7 ; p=0,01$ ) (Quadro 4). Antagonicamente, o risco de colonização por ECN foi $73 \%$ menor em vacas mais velhas do que sete anos em comparação com a faixa etária de referência, mais nova (dois a três anos) (OR=0,27; $\mathrm{IC}_{95 \%}$ $=0,1-0,7 ; p=0,01$ ) (Quadro 5).

\section{Resistência a antimicrobianos e idade/número de par- tos como preditores}

Vacas na faixa etária de quatro a cinco anos tiveram um risco 13,7 vezes maior em relação à faixa etária de dois a três anos de estarem colonizadas por ECP multirresistentes 
Quadro 3. Distribuição de frequência dos animais amostrados categorizados por faixa etária segundo a prevalência de colonização de bactérias e o resultado dos antibiogramas

\begin{tabular}{lccccc}
\hline & & \multicolumn{2}{c}{ Prevalência } & \multicolumn{2}{c}{ Resistência } \\
\cline { 3 - 6 } Faixa Etária & $\begin{array}{c}\text { Número } \\
\text { de animais }\end{array}$ & $\mathrm{ECN}^{\mathrm{a}}$ & $\mathrm{ECP}^{\mathrm{b}}$ & $\begin{array}{c}\text { Bactérias a pelo } \\
\text { menos um antimicrobiano }\end{array}$ & $\begin{array}{c}\mathrm{ECP}^{\mathrm{b}} \\
\text { multirresistentes }\end{array}$ \\
\hline $2-3$ anos & 45 & 31 & 11 & 25 & 1 \\
$4-5$ anos & 49 & 24 & 19 & 33 & 11 \\
$6-7$ anos & 34 & 16 & 11 & 20 & 5 \\
$>7$ anos & 28 & 11 & 15 & 14 & 6 \\
Total & 156 & $84(53,8 \%)$ & $56(35,9 \%)$ & $92(60,1 \%)$ & $23(16,7 \%)$
\end{tabular}

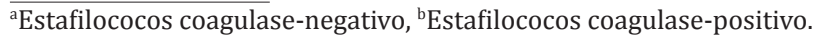

Quadro 4. Resultado da regressão logística para presença de $\operatorname{ECP}^{a}(n=156)$

\begin{tabular}{lcccc}
\hline Faixa Etária & $\mathrm{p}($ wald $)$ & OR $^{\mathrm{b}}$ & \multicolumn{2}{c}{$\mathrm{IC}_{95 \%}$} \\
\hline 2-3 anos & - & 1 & - & - \\
4-5 anos & 0,1392 & 1,958 & 0,804 & 4,768 \\
6-7 anos & 0,4387 & 1,478 & 0,55 & 3,975 \\
$>7$ anos & 0,0133 & 3,566 & 1,303 & 9,761
\end{tabular}

astafilococos coagulase-positivo, ${ }^{\mathrm{b}}$ Odds ratio.

Quadro 5. Resultado da regressão logística para presença de $\operatorname{ECN}^{\mathrm{a}}(\mathrm{n}=156)$

\begin{tabular}{lcccc}
\hline Faixa Etária & $\mathrm{p}$ (wald) & $\mathrm{OR}^{\mathrm{b}}$ & \multicolumn{2}{c}{$\mathrm{IC}_{95 \%}$} \\
\hline 2-3 anos & - & 1 & - & - \\
$4-5$ anos & 0,0523 & 0,434 & 0,187 & 1,088 \\
6-7 anos & 0,0714 & 0,425 & 0,168 & 1,077 \\
$>7$ anos & 0,0101 & 0,276 & 0,104 & 0,736
\end{tabular}

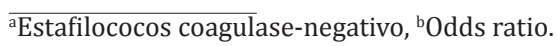

Quadro 6. Resultado da regressão logística para presença de ECP $^{a}$ multirresistentes $(n=156)$

\begin{tabular}{lcccc}
\hline Faixa Etária & $\mathrm{p}($ wald $)$ & $\mathrm{OR}^{\mathrm{b}}$ & \multicolumn{2}{c}{$\mathrm{IC}_{95 \%}$} \\
\hline 2-3 anos & - & 1 & - & - \\
$4-5$ anos & 0,0223 & 13,75 & 1,452 & 130,236 \\
6-7 anos & 0,08 & 8,333 & 0,776 & 89,467 \\
$>7$ anos & 0,106 & 6,667 & 0,668 & 66,532
\end{tabular}

a Estafilococos coagulase-positivo, ${ }^{\mathrm{b}}$ Odds ratio.

Quadro 7. Resultado da regressão logística para presença de bactérias resistentes a pelo menos uma classe de antimicrobianos ( $n=148)$

\begin{tabular}{lcccc}
\hline $\begin{array}{c}\text { Número de } \\
\text { partos }\end{array}$ & $\mathrm{p}$ (wald) & $\mathrm{OR}^{\mathrm{a}}$ & \multicolumn{2}{c}{$\mathrm{IC}_{95 \%}$} \\
\hline $1-2$ & - & 1 & - & - \\
$3-4$ & 0,0268 & 2,713 & 1,122 & 6,564 \\
$>4$ & 0,4936 & 0,762 & 0,35 & 1,66 \\
${ }^{\text {a } \text { Odds ratio. }}$ & & & &
\end{tabular}

$\left(\mathrm{OR}=13,75 ; \mathrm{IC}_{95 \%}\right.$ 1,4-130,2; $\left.\mathrm{p}=0,02\right)$ (Quadro 6). Vacas com três a quatro partos tiveram um risco 2,7 vezes maior do que aquelas com um a dois partos $\left(\mathrm{OR}=2,71 ; \mathrm{IC}_{95 \%} 1,1-6,5\right.$; $p=0,02$ ) de possuírem agentes de mastite com resistência a pelo menos uma classe antimicrobiana (Quadro 7). Neste desfecho, Streptococcus spp. tiveram um maior percentual (83,3\%) (Quadro 2), sendo 60\% destes ambientais (dados não demonstrados). Observou-se uma razão de chances de resistência à tetraciclina em Streptococcus spp. de 14,7 vezes maior que em Staphylococcus spp. pelo teste do qui-quadrado ( $\left.\mathrm{IC}_{95 \%} 4,8-45,0 ; p<0,001\right)$.

\section{DISCUSSÃO}

O plano amostral baseado na estimativa de Staphylococcus spp. resistentes à penicilina levou à coleta de todas as vacas em lactação por rebanho e, por conseguinte, houve uma prevalência maior de bactérias ambientais, predominando os ECN. Os ECN são sabidamente comensais dos tecidos mamários (Taponen \& Pyörälä 2009) e alguns pesquisadores têm apontado seu papel na proteção do úbere contra infecções por bactérias mais patogênicas (Schukken et al. 1989). Curiosamente, a regressão logística evidenciou essa possível dinâmica competitiva nas populações de bactérias conforme a idade das vacas. A definição de quando um animal é considerado "velho" é complexa, mas, de maneira geral, pode ser determinada demograficamente quando apenas $25 \%$ da população estão acima da sua idade (Grundy 2002). Vacas velhas, com mais de sete anos, tiveram menos chances de apresentar ECN e 3,5 vezes mais chances de estarem colonizadas por ECP (ambos $\operatorname{com} p<0,05)$. Mastite bovina é a razão mais comum para o uso de antimicrobianos em vacas leiteiras e a resistência dos agentes etiológicos aos antimicrobianos tem recebido interesse nos últimos anos (Rajala-Schultz et al. 2004) devido às terapias ineficazes ou subterapêuticas dadas aos rebanhos (Erskine et al. 2002). A terapia no período seco de lactação é executada em todas as vacas na maioria das propriedades e consiste em formulações com atividade antimicrobiana prolongada. A persistência deste tipo de tratamento deve, portanto, proporcionar uma forte pressão seletiva para a aquisição, transmissão e manutenção de genes de resistência a drogas (Berghash et al. 1983). A hipótese deste estudo foi relativa à resistência ser maior em bactérias de multíparas em comparação às de primíparas devido ao período de pressão seletiva por exposição a antimicrobianos. Isto foi verificado em duas instâncias, entre todas as bactérias testadas resistentes a pelo menos um antimicrobiano, com maior risco nas multíparas com três ou quatro partos comparadas às primíparas com um ou dois partos; e entre ECP multirresistentes, com maior risco na faixa etária de três a quatro anos comparadas à faixa etária de um a dois anos.

A suscetibilidade antimicrobiana in vitro é uma condição prévia ao tratamento, mas não garante a eficácia in vivo (Constable \& Morin 2003). A resistência a antimicrobianos resulta de interações entre antibióticos, microrganismos e ambiente (Witte 2000, Levin 2001, O'Brien 2002). Dois fatores envolvidos são a pressão seletiva dos antibióticos e a 
presença de genes de resistência (Levy 1997, Witte 2000), que podem ser transmitidos verticalmente ou por transferência horizontal de elementos móveis de DNA (Chambers 2001, Sefton 2002). A exposição a concentrações insuficientes da droga proporciona a chamada janela de seleção (Burgess 1999). Streptococcus spp. apresentaram mais chances de serem resistentes à tetraciclina comparados aos Staphylococcus spp. Dentre todas as bactérias testadas, vacas com três ou quatro partos tiveram 2,7 mais chances que o grupo com menos partos - um ou dois - de estarem colonizadas por bactérias resistentes a pelo menos uma classe antibiótica (Quadro 7). Observou-se uma curva de risco típica da presença de resistência a pelo menos uma classe antimicrobiana no decorrer das três classes de partos, com menor risco nas com um ou dois partos, maior nas vacas com três ou quatro $(\mathrm{OR}=2,7)$ e menor novamente nas com mais de quatro $(\mathrm{OR}=0,7)$. Isso pode estar relacionado à eliminação de animais velhos com infecção crônica, ou por outras causas, que normalmente seleciona o melhor estrato de animais.

A resistência de $S$. aureus às penicilinas tem aumentado (Piddock 1996, Olsen et al. 2006) porque, de um modo geral, a terapia é ineficiente pelo acesso antimicrobiano às bactérias ser dificultado por fibroses decorrentes da patogenia (Radostits et al. 1994), além de tratamentos ineficazes ou incompletos. As taxas de cura variam entre 15 e 85\%, dependendo do número de lactações, contagem de células somáticas antes do tratamento e produção de $\beta$-lactamase (Barkema et al. 2006). Em muitos casos, os animais tornam-se cronicamente infectados e reservatórios de $S$. aureus. No presente estudo a prevalência de colonização por ECP de $21 \%$ foi obtida a partir da população amostrada em lactação desconsiderando o seu estado clínico.

Quanto à resistência à penicilina por $S$. aureus, esta costuma ser menor do que em ECN, salvo exceções (Pitkälä et al. 2004, Schwarz et al. 2010). Na Índia, por exemplo, os resultados variaram largamente (Mubarack et al. 2012, Mohanty et al. 2013) e estudos no Brasil com amostras não planejadas mostram variabilidade no padrão de resistência (Oliveira et al. 2012, Silva et al. 2012), e aumento quando comparados com estudos mais antigos (Brito et al. 2001). Entretanto, de maneira geral, fica deficiente a comparação dos resultados devido a diferenças na metodologia, principalmente devido a critérios de amostragem, e servem apenas como referência. Resistência à penicilina por ECN de mastite bovina foi $31,7 \%$ em Ohio, EUA (Rajala-Schultz et al. 2004) e 32\% na Finlândia (Pitkälä et al. 2004). Pesquisadores suecos (Persson Waller et al. 2011) relatam que não houve muita resistência a antimicrobianos em estudo, com exceção à penicilina, por ECN em mastites clínicas e subclínicas, o que é corroborado em nosso estudo, em que a resistência por ECN ao grupo das penicilinas foi 48,8\%, embora também houve resistência considerável à eritromicina $(41,6 \%)$. Pesquisadores estadunidenses de Ohio (Rajala-Schultz et al. 2004) encontraram $43,9 \%$ de resistência a pelo menos um antibiótico por ECN, e indicam o uso de terapias no período seco como sendo fator de risco para o aparecimento de resistência (Rajala-Schultz et al.
2009). Em estudo na Holanda, 30\% de ECN foram resistentes a mais de um composto antimicrobiano em rebanhos leiteiros (Sampimon 2009). Estes resultados estão em consonância com um estudo que avaliou a correlação entre o uso de antimicrobianos veterinários e a resistência antimicrobiana em animais de produção de sete países europeus (Chantziaras et al. 2014), sendo a Holanda um dos maiores consumidores de antimicrobianos e os países nórdicos, uns dos menores. Encontramos resistência a pelo menos uma classe de antimicrobianos em 55,9\% dos ECN testados e, a três ou mais classes, em 23,8\% (Quadro 2). A coleta de dados de consumo de antimicrobianos através de um sistema de armazenamento padrão a nível populacional é altamente recomendável para elucidação dos níveis de resistência encontrados.

Eritromicina e clindamicina estão entre os fármacos selecionados para o tratamento de mastite bovina estafilocócica (Dingwell et al. 2003, Yu \& Li 2005) e a resistência a eles ocorre por metilação ou mutação do sítio alvo, ativação do efluxo do antibiótico, e inativação da droga. Pesquisadores chineses (Wang et al. 2008) verificaram resistência à eritromicina $-93,1 \%$ e à clindamicina $-36,1 \%$ por $S$. aureus mais elevada que neste estudo, $46,3 \%$ e $31,7 \%$, respectivamente (Quadro 2), porém tais antimicrobianos foram aprovados na China para o tratamento de mastite estafilocócica. Resistência por ECN a macrolídeos e lincosamidas foi relatada na Alemanha em 6-7\% (Lüthje \& Schwarz 2006). Obtiveram-se valores de resistência à eritromicina e à clindamicina por ECN de $41,6 \%$ e $16,6 \%$, respectivamente. Os macrolídeos, bem como as fluorquinolonas e as cefalosporinas de $3^{3}$ e $4^{a}$ geração, têm sido listados como criticamente importantes à saúde pública pela Organização Mundial da Saúde, por serem as únicas ou umas das poucas alternativas para tratar doenças humanas severas e causadas por microrganismos de fontes não humanas ou que possam adquirir genes de resistência de fontes não humanas (WHO 2011).

Entre os objetivos da epidemiologia, o conhecimento da distribuição das doenças em populações nos diferentes estratos de idade é particularmente relevante para estimação de morbimortalidades e identificação de causas (Thrusfield 2007). A epidemiologia é baseada na premissa de que doença e saúde não são distribuídas aleatoriamente na população, e é função da epidemiologia identificar padrões das doenças e fatores causais associados, alguns dos quais são relacionados à idade (Satariano 2006). A idade é frequentemente classificada como um fator predisponente, refletindo um conhecimento inadequado do seu papel nos níveis celular, molecular e bioquímico (Thrusfield 2010). A regressão logística evidenciou associação significativa entre a presença de ECP multirresistentes e a idade dos bovinos em lactação, especificamente na faixa intermediária de quatro a cinco anos que coincide com a idade média dos animais (5,2 anos). A chance de colonização por cepas de ECP multirresistentes foi 13,7 vezes maior do que aquelas com dois a três anos. Tal fato pode estar relacionado às chances de animais velhos, comparados aos de primeira lactação, terem tido maior contato com cepas resistentes (Rajala-Schultz et al. 2004). 


\section{CONCLUSÕES}

Este trabalho verificou a distribuição de bactérias colonizadoras da glândula mamária segundo a idade de vacas leiteiras amostradas independentemente do estado clínico.

As regressões logísticas evidenciaram que há menor razão de chances de colonização por ECN e maior razão de chances por ECP em animais mais velhos comparados aos mais novos.

A prevalência poderia aumentar devido à perda de cepas suscetíveis que são repostas por cepas carreando e expressando resistência em resposta aos tratamentos antimicrobianos.

É possível que exista uma complexa dinâmica de competição entre bactérias comensais e patogênicas durante a vida produtiva de vacas leiteiras, por meio de interações seletivas de antimicrobianos.

A resistência identificada nas classes intermediárias (etária e número de partos) levanta a hipótese de uma convergência do ápice da produção de leite e estado imunitário do hospedeiro com a exposição a patógenos e consecutivos tratamentos antimicrobianos numa escala populacional.

Conforme o passar dos anos, há o descarte sistemático de animais debilitados por mastite ou outras enfermidades, justificando o baixo risco de colonização por bactérias resistentes nas vacas mais velhas.

A resistência a fármacos de importância crítica no tratamento de enfermidades em humanos representa um importante risco à saúde pública.

0 uso de antimicrobianos deve ser extremamente criterioso e o uso preventivo, abolido, como tem sido feito em outras cadeias de produção animal, a fim de interromper o estímulo à resistência.

Além disso, propõe-se a adoção da idade como parâmetro nos estudos populacionais de resistência a antimicrobianos, visto a distribuição heterogênea nas faixas etárias de bovinos.

\section{REFERÊNCIAS}

Barkema H.W., Schukken Y.H. \& Zadocks R.N. 2006. Invited review: the role of cow, pathogen, and treatment regimen in the therapeutic success of bovine Staphylococcus aureus mastitis. J. Dairy Sci. 89:1877-1895. (Apud Taponen \& Pyörälä 2009)

Berghash S.R., Davidson J.N., Armstrong J.C. \& Dunny G.M. 1983. Effects of antibiotic treatment of nonlactating dairy cows on antibiotic resistance patterns of bovine mastitis pathogens. Antimicrob. Agents Chemother. 24(5): 771-776. (Apud Erskine et al. 2002)

Burgess D.S. 1999. Pharmacodynamic principles of antimicrobial therapy in the prevention of resistance. Chest 115: 195-233. (Apud Guardabassi et al. 2010)

Brito M.A.V.P., Brito J.R.F., Silva M.A.S. \& Carmo R.A. 2001. Concentração mínima inibitória de dez antimicrobianos para amostras de Staphylococcus aureus isoladas de infecção intramamária bovina. Arq. Bras. Med. Vet. Zootec. 53(5):531-537.

Chambers H.F. 2001. Antimicrobial agents: general considerations, p.1143-1170. In: Hardman J.G. \& Limbird L.E. (Eds), Goodman and Gilman's The Pharmacological Basis of Therapeutics. McGraw-Hill, New York. (Apud Rajala-Schultz et. al 2004)

Chantziaras I., Bayen F., Callens B. \& Dewulf J. 2014. Correlation between veterinary antimicrobial use and antimicrobial resistance in food-producing animals: a report on seven countries. J. Antimicrob. Chemother. 69(3):827-834.
CLSI 2008. Performance standards for antimicrobial disk and dilution susceptibility tests for bacteria isolated from animals; approved standard. $3^{\text {rd }}$ ed. CLSI Document M31-A3. Clinical and Laboratory Standards Institute, Wayne, PA.

Constable P.D. \& Morin D.E. 2003. Treatment of clinical mastitis: using antimicrobial susceptibility profiles for treatment decisions. In: Sears P. Guest (Ed.), Bovine Mastitis. Vet. Clin. North Am., Food Anim. Pract. 19:139-55. (Apud Guardabassi et al. 2010)

Dingwell R., Leslie K.E., Duffield T.F., Schukken Y.H., DesCoteaux L., Keefe G.P., Kelton D.F., Lissemore K.D., Shewfelt W., Dick P. \& Bagg R. 2003. Efficacy of intramammary tilmicosin and risk factors for cure of Staphylococcus aureus infection in the dry period. J. Dairy Sci. 86:159-168.

Erskine R., Cullor J., Schaellibaum M., Yancey B. \& Zecconil A. 2004. Bovine mastitis pathogens and trends in resistance to antibacterial drugs. In: Proc. $43^{\text {rd }}$ National Mastitis Council Annual Meeting, Charlotte, NC, p.400-414.

Erskine R.J., Walker R.D., Bolin C.A., Bartlett P.C. \& White D.G. 2002. Trends in antibacterial sucetibility of matitis pathogens during a seven-year period. J. Dairy Sci. 85:1111-1118.

Grundy E.M.D. 2002. The epidemiology of aging, p.3-20. In: Tallis R.C. \& Fillit H.M. (Eds), Brockelhurst's Textbook of Geriatric Medicine and Gerontology. $6^{\text {th }}$ ed. Churchill Livingstone, London. (Apud Thrusfield 2010)

Guardabassi L., Jensen L.B. \& Kruse H. 2010. Guia de Antimicrobianos em Veterinária. Artmed, Porto Alegre. 267p.

Levin B.R. 2001. Minimizing potential resistance: a population dynamics view. Clin. Infect. Dis. 33(3):161-169.

Levy S.B. 1997. Antibiotic resistance: an ecological imbalance, p.1-14. In: Chadwick D.J. \& Goode J. (Eds), Antibiotic Resistance: origins, evolution, selection and spread. 207 $7^{\text {th }}$ Ciba Foundation Symposium, Wiley, Chichester.

Lüthje P. \& Schwarz S. 2006. Antimicrobial resistance of coagulase-negative staphylococci from bovine subclinical mastitis with particular reference to macrolide-lincosamide resistance phenotypes and genotypes. J. Antimicrob. Chemother. 57:966-969.

Mohanty N.N., Das P., Pany S.S., Sarangi L.N., Ranabijuli S. \& Panda H.K. 2013. Isolation and antibiogram of Staphilococcus, Streptococcus and Escherichia coli isolates from clinical and subclinical cases of bovine mastitis. Vet. World 6(10):739-743.

Mubarack H.M., Doss A., Vijayasanthi M. \& Venkataswamy R. 2012. Antimicrobial drug susceptibility of Staphylococcus aureus from subclinical bovine mastitis in Coimbatore, Tamilnadu, South India. Vet. World 5(6):352-355.

National Mastitis Council 2004. Microbiological Procedures for the Diagnosis of Bovine Udder Infection and Determination of Milk Quality. $4^{\text {th }}$ ed. NMC, Verona. 47p.

O’Brien T.F. 2002. Emergence, spread, and environmental effect of antimicrobial resistance: how use of an antimicrobial anywhere can increase resistance to any antimicrobial anywhere else. Clin. Infect. Dis. 34(3):78-84. (Apud Rajala-Schultz et. al 2004)

OIE 2008a. Harmonisation of national antimicrobial resistance surveillance and monitoring programs, p.1-7. In: Ibid. (Ed.), Terrestrial Animal Health Code. OIE, Paris. Disponível em <http://www.oie.int/eng/nor-mes/Mcode/en_sommaire.htm> Acesso em 20 nov. 2011.

OIE 2008b. Risk assessment for antimicrobial resistance arising from the use of antimicrobials in animals, p.1-6. In: Ibid. (Ed.), Terrestrial Animal Health Code. World Organization for Animal Health, Paris. Disponível em <http://www.oie.int/eng/nor-mes/Mcode/en_sommaire.htm> Aces-so em 20 nov. 2011.

Oliveira U.V., Galvão G.S., Ribeiro A.R.P., Andrioli J.L. \& Munhoz A.D. 2012. Eficácia in vitro da gentamicina sobre bactérias isoladas de vacas com mastite subclínica na microrregião Ilhéus-Itabuna, Bahia. Revta Bras. Med. Vet. 34(3):213-218.

Olsen J.E., Christensen H. \& Aarestrup F.M. 2006. Diversity and evolution of blaZ from Staphylococcus aureus and coagulase-negative staphylococci. J. Antimicrob. Chemother. 57:450-460. 
Persson Waller K., Aspán A., Nyman A., Persson Y. \& Grönlund Andersson U. 2011. CNS species and antimicrobial resistance in clinical and subclinical bovine mastitis. Vet. Microbiol. 152:112-116.

Piddock L.J.V. 1996. Does the use of antimicrobial agents in veterinary medicine and animal husbandry select antibiotic-resistant bacteria that infect man and compromise antimicrobial therapy? J. Antimicrob. Chemother. 38:1-3. (Apud Guardabassi et al. 2010)

Pitkälä A., Haveri M., Pyorala S., Myllys V. \& Honkanen-Buzalski T. 2004. Bovine mastitis in Finland 2001: prevalence, distribution of bacteria and antimicrobial resistance. J. Dairy Sci. 87:2433-2441.

Radostits O.M., Leslie K.E. \& Fetrow J. 1994. Mastitis control in dairy herds, p.229-276. In: Radostitis O.M., Leslie K.E. \& Fetrow J. (Eds), Herd Health Food Animal Production Medicine. Philadelphia: W.B. Saunders, Philladelphia.

Rajala-Schultz P.J., Smith K.L., Hogan J.S. \& Love B.C. 2004. Antimicrobial susceptibility of mastitis pathogens from first lactation and older cows. Vet. Microbiol. 102:33-42.

Rajala-Schultz P.J., Torres A.H., DeGraves F.J., Gebreyes W.A. \& Patchanee P. 2009. Antimicrobial resistance and genotypic characterization of coagulase-negative staphylococci over the dry period. Vet. Microbiol. 134:55-64.

Ruegg P.L. 2012. New perspective in udder health management. Vet. Clin. North Am., Food Anim. Pract. 28:149-163.

Sampimon O.C. 2009. Coagulase-negative staphylococci mastitis in Dutch dairy herds. Thesis, Dutch Animal Health Service (GD), Deventer, The Netherlands.

Schwarz S., Silley P., Simjee S., Woodfords N., Van Duijkeren E., Johnson A.P. \& Gaastra W. 2010. Assessing the susceptibility of bacteria obtained from animals. J. Antimicrob. Chemother. 65:601-604.
Schukken Y.H., Van de Geer D., Grommers F.J., Smit J.A.H. \& Brand A. 1989. Intramammary infections and risk factors for clinical mastitis in herds with low somatic cell counts in bulk milk. Vet. Rec. 125:393-396. (Apud Rajala-Schultz et al. 2004)

Sefton A.M. 2002. Mechanisms of antimicrobial resistance: their clinical relevance in the new millennium. Drugs 62:557-566. (Apud Rajala-Schultz et al. 2004)

Silva E.R., Pereira A.M.G., Moraes W.S., Santoro K.R. \& Silva T.R.M. 2012. Perfil de sensibilidade antimicrobiana in vitro de Staphylococcus aureus isolado de mastite subclínica bovina. Revta Bras. Saúde Prod. Anim. 13(3):701-711.

Taponen S. \& Pyörälä S. 2009. Coagulase-negative staphylococci as cause of bovine mastitis: not so different from Staphylococcus aureus? Vet. Microbiol. 134:29-36.

Thrusfield M.V. 2007. Veterinary Epidemiolog. $3^{\text {rd }}$ ed. Blackwell Science, Oxford, p.22-33.

Thrusfield M.V. 2010. Ageing in Animal Populations: an epidemiological perspective. J. Comp. Pathol. 142:S22-S32.

Wang Y., Wu C.M., Lu L.M., Ren G.W.N., Cao X.Y. \& Shen J.Z. 2008. Macrolidelincosamide-resistant phenotypes and genotypes of Staphylococcus aureus isolated from bovine clinical mastitis. Vet. Microbiol. 130:118-125.

WHO 2011. Critically Important Antimicrobials for Human Medicine. 3rd ed. <http://who.int/foodborne_disease/resistance/cia/en> Acessado em 14 fev. 2014).

Witte W. 2000. Ecological impact of antibiotic use in animals on different complex microflora: environment. Int. J. Antimicrob. Agents 14:321325. (Apud Rajala-Schultz et al. 2004)

Yu Y. \& Li J.S. 2005. The curative effects of clindamycin hydrochloride on dairly acute mastadenitis. Chin. J. Vet. Drug 39:37-42. 